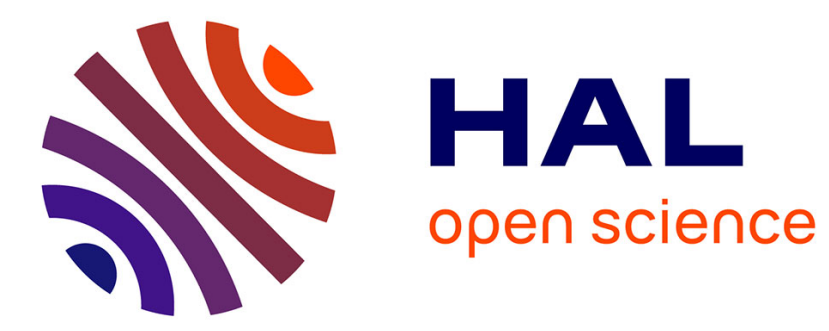

\title{
Local order and magnetic behavior of amorphous and nanocrystalline yttrium iron garnet produced by swift heavy ion irradiations
}

Jean-Marc Constantini, Jean-Michel Desvignes, Alain Pérez, F. Studer

\section{- To cite this version:}

Jean-Marc Constantini, Jean-Michel Desvignes, Alain Pérez, F. Studer. Local order and magnetic behavior of amorphous and nanocrystalline yttrium iron garnet produced by swift heavy ion irradiations. Journal of Applied Physics, 2000, 87 (4), pp.1899-1907. 10.1063/1.372110 . hal-00906590

\section{HAL Id: hal-00906590 \\ https://hal-iogs.archives-ouvertes.fr/hal-00906590}

Submitted on 20 Nov 2013

HAL is a multi-disciplinary open access archive for the deposit and dissemination of scientific research documents, whether they are published or not. The documents may come from teaching and research institutions in France or abroad, or from public or private research centers.
L'archive ouverte pluridisciplinaire HAL, est destinée au dépôt et à la diffusion de documents scientifiques de niveau recherche, publiés ou non, émanant des établissements d'enseignement et de recherche français ou étrangers, des laboratoires publics ou privés. 


\title{
Local order and magnetic behavior of amorphous and nanocrystalline yttrium iron garnet produced by swift heavy ion irradiations
}

\author{
J. M. Costantinia) \\ CEA, DPTA/SPMC, BP 12, F-91680, Bruyères-le-Châtel, France \\ J. M. Desvignes \\ CNRS, Laboratoire Charles Fabry, IOTA F-91403, Orsay Cedex, France \\ A. Pérez \\ Départment de Physique des Matériaux, Université Claude Bernard, Lyon-I F-69622, \\ Villeurbanne Cedex, France \\ F. Studer \\ CNRS, CRISMAT/ISMRa, 6, Boulevard Maréchal Juin, F-14050, Caen Cedex, France
}

(Received 20 April 1999; accepted for publication 28 October 1999)

Thin epitaxial films of gallium or scandium-doped and undoped yttrium iron garnet $\left(\mathrm{Y}_{3} \mathrm{Fe}_{5} \mathrm{O}_{12}\right.$ or YIG) on nonmagnetic $\mathrm{Gd}_{3} \mathrm{Ga}_{5} \mathrm{O}_{12}$ substrates were irradiated with swift heavy ions $\left(50 \mathrm{MeV}^{32} \mathrm{~S}\right.$, $50 \mathrm{MeV}{ }^{63} \mathrm{Cu}$, and $235 \mathrm{MeV}{ }^{84} \mathrm{Kr}$ ) in the electronic slowing down regime. The mean electronic stopping power in the films was always larger than the threshold for amorphous track formation in YIG which is around $4.5 \mathrm{MeV} / \mu \mathrm{m}$ in this low ion-velocity range. The local order and magnetic properties of the damaged films were then studied at room temperature by ${ }^{57} \mathrm{Fe}$ conversion electron Mössbauer spectroscopy (CEMS) and x-ray absorption spectroscopy (XAS) at the iron $K$ edge in the fluorescence mode. In the case of paramagnetic gallium or scandium-substituted films (YIG:Ga, YIG:Sc) irradiated with ${ }^{32} \mathrm{~S}$ or ${ }^{63} \mathrm{Cu}$ ions, the CEMS data show that the tetrahedral $\mathrm{Fe}^{3+}$ sites are preferentially damaged, while the octahedral sites are conserved. This is confirmed by the decrease of the pre-edge peak in the XAS data of the ferrimagnetic undoped YIG films showing that the number of tetrahedral iron sites is decreased in the amorphous phase obtained with ${ }^{84} \mathrm{Kr}$ ion irradiation, due to the formation of fivefold-coordinated pyramidal sites, as already found in a previous study on undoped YIG sinters amorphized by $3.5 \mathrm{GeV}^{132} \mathrm{Xe}$ ion irradiation. In the case of the nanophase induced by ion-beam recrystallization of the tracks with ${ }^{32} \mathrm{~S}$ or ${ }^{63} \mathrm{Cu}$ irradiations, a further decrease of the pre-edge peak is found. This is interpreted by (i) an increase of the fivefold-coordinated pyramidal sites and/or (ii) a probable decomposition of the garnet into orthoferrite $\left(\mathrm{YFeO}_{3}\right)$ and haematite $\left(\alpha-\mathrm{Fe}_{2} \mathrm{O}_{3}\right)$ under the high-pressure and high-temperature conditions in the thermal spike generated by the ions. The CEMS data of irradiated undoped YIG also show that both the amorphous and nanocrystalline phases have a paramagnetic behavior at room temperature. The nanophase magnetic behavior is analyzed on the basis of a superparamagnetic relaxation above the blocking temperature, whereas the amorphous phase behavior is ascribed to a speromagnetic state. (C) 2000 American Institute of Physics. [S0021-8979(00)01404-3]

\section{INTRODUCTION}

Swift heavy ion irradiations of magnetic insulators have been extensively studied over the last twenty years. It has been shown that amorphous latent tracks are produced above a threshold of the electronic stopping power $S_{e}$ $=(-d E / d x)_{e}$, corresponding to a large density of ionizations and electronic excitations. ${ }^{1}$ Track production was also devised in order to modify the material properties. In particular, yttrium iron garnet $\left(\mathrm{Y}_{3} \mathrm{Fe}_{5} \mathrm{O}_{12}\right.$ or $\left.\mathrm{YIG}\right)$ was given much attention due to its interesting magnetic and magneto-optical properties that can be tailored in this way. ${ }^{2}$ The amorphous track production threshold is around $4.5 \mathrm{MeV} / \mu \mathrm{m}$ in this

\footnotetext{
a) Author to whom correspondence should be addressed; electronic mail: costantini@drnsac.cea.fr at CEA/SACLAY, DMT/SEMI, F-31131, GiFSUR-YVETTE Cedex, France
}

case, in the low ion velocity range, and around $7 \mathrm{MeV} / \mu \mathrm{m}$ in the high-velocity range. ${ }^{3}$ The latter velocity effect was interpreted by using a thermal spike model taking account of the radial distribution profile of the excitation energy deposited on the electronic subsystem. ${ }^{3,4}$

The amorphous phase ( $a$-YIG) produced by irradiations of bulk undoped YIG sinters in the high-velocity range (3.5 $\mathrm{GeV}{ }^{132} \mathrm{Xe}, S_{e}=36 \mathrm{MeV} / \mu \mathrm{m}$ ) was studied on the basis of the ${ }^{57} \mathrm{Fe}$ Mössbauer and X-ray absorption spectroscopy data. ${ }^{5} \mathrm{It}$ was shown that the tetrahedral iron sites are preferentially destroyed in the damage process and that new fivefoldcoordinated sites are formed in the amorphous phase. We have also shown by high-resolution transmission electron microscopy (HRTEM) that, in the low ion velocity range, recrystallization of the amorphous tracks occurs in undoped YIG thin epitaxial films due to track overlap at a low 
fluence. ${ }^{6,7}$ A nanocrystalline phase is then produced under the ion beams with grain sizes around $10 \mathrm{~nm}^{6}$ and a much larger electrical conductivity. ${ }^{7}$ The nanograins are embedded within a matrix made of amorphous and single-crystalline YIG with relative fractions depending on the fluence and $\mathrm{S}_{\mathrm{e}}{ }^{6}$ At a fluence of $4.5 \times 10^{12} \mathrm{~cm}^{-2}$ with $50 \mathrm{MeV}{ }^{63} \mathrm{Cu}$ ion irradiations (90\% of amorphous phase), the nanograins are widely separated with an average distance around $20 \mathrm{~nm}$ that decreases at higher fluence when the recrystallization proceeds. ${ }^{6}$ The thermal spike model was then adapted to interpret the nanophase formation from the amorphous phase in the same way as was done in the case of amorphous track formation. ${ }^{7}$ It was also found that $p$ - or $n$-type doping of the YIG films respectively with divalent $\left(\mathrm{Ca}^{2+}\right)$ or tetravalent $\left(\mathrm{Si}^{4+}\right)$ ions did not change the amorphization and recrystallization processes in the thin films, although the electrical conductivity of the pristine films was increased up to eight orders of magnitude. ${ }^{8,9}$

In this work, we wanted to address the problem of the local atomic order in the amorphous and nanocrystalline phases obtained by swift heavy-ion irradiations of YIG. For this purpose, room-temperature ${ }^{57} \mathrm{Fe}$ Mössbauer and x-ray absorption measurements were performed on gallium or scandium-doped and undoped YIG epitaxial films irradiated in the low ion velocity range, in the same way as was previously done with bulk undoped YIG samples irradiated in the high-velocity range. ${ }^{5}$ However, contrary to the latter study, we have used doped YIG thin films that are paramagnetic and have simpler Mössbauer spectra, in order to see clearly any modification of the iron site distribution and/or oxidation state. In order to have an homogeneous damage in this case, it was necessary to use epitaxial films a few $\mu \mathrm{m}$ thick so that the low-velocity heavy ions were transmitted through the samples with a mean electronic stopping power larger than the amorphous track formation threshold.

\section{EXPERIMENTAL SECTION}

We have used thin epitaxial layers of yttrium iron garnet $\left(\mathrm{Y}_{3} \mathrm{Fe}_{5} \mathrm{O}_{12}\right.$ or $\left.\mathrm{YIG}\right)$ grown on (111)-gadolinium gallium garnet $\left(\mathrm{Gd}_{3} \mathrm{Ga}_{5} \mathrm{O}_{12}\right.$ or GGG; $\left.a_{s}=12.383 \AA\right)$ substrates with the liquid phase epitaxy technique in a $\mathrm{PbO}+\mathrm{B}_{2} \mathrm{O}_{3}$ solvent at a growth temperature around $850^{\circ} \mathrm{C} .{ }^{10}$ Undoped YIG films have been grown as well as films doped with gallium $\left(\mathrm{Y}_{2.7} \mathrm{La}_{0.30} \mathrm{Fe}_{2.84} \mathrm{Ga}_{2.16} \mathrm{O}_{12}\right.$ or YIG:Ga). The substitution of yttrium by lanthanum was used to reduce the film mismatch with the GGG lattice parameter $\left(a_{s}\right)$ by increasing the film lattice parameter. ${ }^{11}$ Some ${ }^{57} \mathrm{Fe}$-enriched YIG films doped with scandium $\left(\mathrm{Y}_{2.9} \mathrm{La}_{0.1} \mathrm{Fe}_{3.5} \mathrm{Sc}_{1.5} \mathrm{O}_{12}\right.$ or YIG:Sc) have also been prepared in a different way in a lithium and rare-earth molybdate solvent at a growth temperature around $1000^{\circ} \mathrm{C}$ on a SGGG (GGG:Ca, Zr; $a_{s}=12.496 \AA$ ) substrate. ${ }^{11}$ Both sides of the substrates were coated with film thicknesses ranging between around 2 and $10 \mu \mathrm{m}$, whereas the substrate thickness was always of $500 \mu \mathrm{m}$. The $2 \mathrm{in}$. wafers were cut into $1 \mathrm{~cm}^{2}$ square samples for this study.

The ${ }^{57} \mathrm{Fe}$ conversion-electron Mössbauer (CEM) spectra were measured at room temperature using a ${ }^{57} \mathrm{CoRh}$ source and constant acceleration triangular drive. ${ }^{12}$ The isomer
TABLE I. Hyperfine parameters used for the least-squares fits of the $300 \mathrm{~K}$ ${ }^{57} \mathrm{Fe}$ CEM spectrum of the ferrimagnetic pristine undoped (111)-YIG epitaxial film [Fig. 1(a)]: isomer shift (I.S.), effective hyperfine magnetic field $\left(H_{\mathrm{hf}}\right)$, quadrupolar shift $(2 \epsilon)$, full width at half maximum $(\Gamma)$, areal ratio of the second or fifth lines to the first or sixth lines $\left(A_{2,5} / A_{1,6}\right)$, and fraction $(R)$ of the ion sites. The standard deviation is $0.01 \mathrm{~mm} / \mathrm{s}$ on the I.S. and $2 \epsilon$ values, and $0.2 \mathrm{~T}$ on the $H_{\mathrm{hf}}$ values.

\begin{tabular}{rcccccc}
\hline \hline & I.S. & $H_{\mathrm{hf}}$ & $2 \epsilon$ & $A_{2,5} / A_{1,6}$ & $\Gamma$ & $R$ \\
\hline & {$[\mathrm{mm} / \mathrm{s}]$} & {$[\mathrm{T}]$} & {$[\mathrm{mm} / \mathrm{s}]$} & & {$[\mathrm{mm} / \mathrm{s}]$} & $\%$ \\
Octahedral sites $(a)$ & 0.50 & 49.7 & 0.17 & 1.11 & 0.40 & 34 \\
$\left(a^{\prime}\right)$ & 0.51 & 48.2 & -0.22 & 1.02 & 0.38 & 11 \\
Tetrahedral sites $(d)$ & 0.24 & 40.7 & 0.02 & 0.84 & 0.39 & 30 \\
$\left(d^{\prime}\right)$ & 0.27 & 38.7 & 0.0 & 1.50 & 0.42 & 25 \\
\hline
\end{tabular}

shifts (I.S.) are corrected for the I.S. of metallic iron $(0.115$ $\mathrm{mm} / \mathrm{s}$ ) taken as a reference. The $300 \mathrm{~K}$ CEM spectra of the as-grown undoped (111)-YIG films exhibit a magnetic hyperfine field splitting composed of four sextets due to the octahedral $(16 a)$ and tetrahedral $(24 \mathrm{~d}) \mathrm{Fe}^{3+}$ lattice sites [Table I and Fig. 1(a)]. ${ }^{12}$ From the areal ratios of the second or fifth lines to the first or sixth lines $\left(A_{2,5} / A_{1,6}\right)$, it is concluded that the magnetization makes an angle around $70^{\circ}$ relative to the sample surface normal. ${ }^{12}$ It is known indeed that YIG is a ferrimagnet with a Curie temperature $\left(T_{C}\right)$ of $550 \mathrm{~K}$, while GGG is nonmagnetic (antiferromagnetic ordering of the gadolinium sublattice occurs at a Néel temperature of $10 \mathrm{~K}) .{ }^{13}$ By substituting $\mathrm{Fe}^{3+}$ with diamagnetic trivalent cations like $\mathrm{Ga}^{3+}$ and $\mathrm{Sc}^{3+}, T_{C}$ decreases so that the YIG:Ga and YIG:Sc can become paramagnetic at $300 \mathrm{~K}$ for a large impurity concentration. ${ }^{13}$ This is clearly seen in the $300 \mathrm{~K}$ ${ }^{57} \mathrm{Fe}$ CEM spectra of the as-grown (111)-oriented epilayers which exhibit only two quadrupolar doublets corresponding respectively to the octahedral and tetrahedral $\mathrm{Fe}^{3+}$ lattice sites, and no magnetic hyperfine field splitting [Figs. 2-4(a)]. Also, for YIG:Ga, the plot of the magnetization versus temperature shows that $T_{C}$ is around $210 \mathrm{~K}$ in agreement with literature data, while for YIG:Sc, $T_{C}$ is given to be $100 \mathrm{~K}^{13}$ The CEM spectra of YIG:Ga and YIG:Sc look different because $\mathrm{Ga}^{3+}$ sits preferentially in the tetrahedral sites while $\mathrm{Sc}^{3+}$ sits in the octahedral ones. ${ }^{13}$ The latter effect is further enhanced by the lanthanum substitutions. ${ }^{11}$ The least-squares fit of the spectra give the site distributions for YIG:Ga $($ octa/tetra $=60: 40)$ and YIG:Sc (octa/tetra $=10: 90)$ (Tables II-IV).

The doped films were irradiated at $300 \mathrm{~K}$ with $50 \mathrm{MeV}$ ${ }^{32} \mathrm{~S}$ and $50 \mathrm{MeV}{ }^{63} \mathrm{Cu}$ ions at the Van de Graaff Tandem accelerator in CEA Bruyères-le-Châtel, France. The undoped ones were irradiated at $300 \mathrm{~K}$ with $50 \mathrm{MeV}^{32} \mathrm{~S}$ and $50 \mathrm{MeV}$ ${ }^{63} \mathrm{Cu}$ ions, and with $235 \mathrm{MeV}{ }^{84} \mathrm{Kr}$ ions at the SARA facility in Grenoble, France. The ion beams were swept over the sample surface in order to obtain uniform irradiations. Owing to the low beam current densities $\left(\leqslant 30 \mathrm{nA} / \mathrm{cm}^{2}\right)$, only a small temperature rise around $20 \mathrm{~K}$ was found during the irradiations. The ion fluences were monitored by recording the backscattered ion spectra on a 100-nm-thick gold layer ring around the sample. A quantitative calibration was performed by measuring the beam current with a Faraday cup in the same beam conditions. Only one epitaxial film on one 


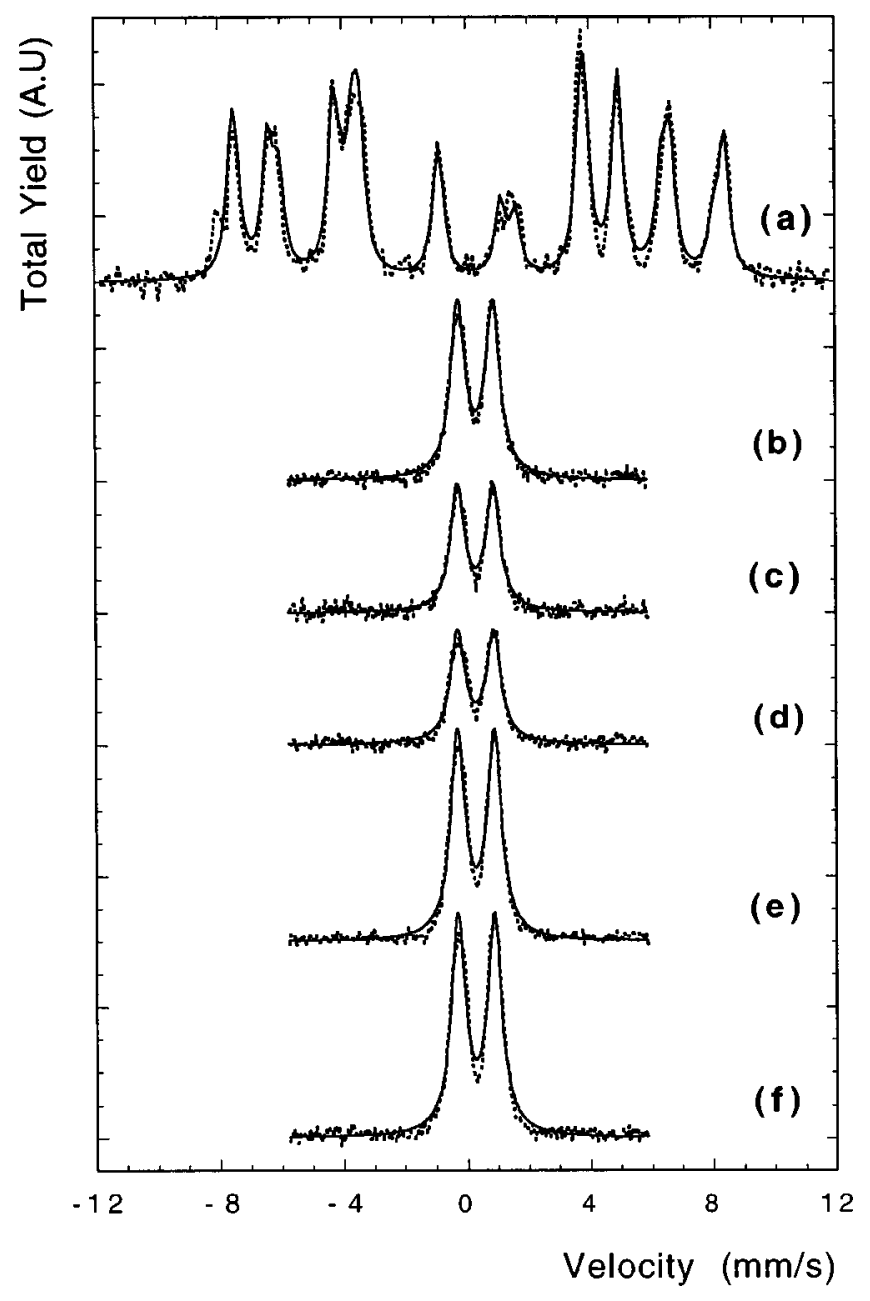

FIG. 1. $300 \mathrm{~K}$ conversion electron Mössbauer spectra of undoped (111)YIG thin epitaxial films; as-grown (a), irradiated with $50 \mathrm{MeV}{ }^{32} \mathrm{~S}$ ions: $3.7 \times 10^{14} \mathrm{~cm}^{-2}$ (b), $7.0 \times 10^{14} \mathrm{~cm}^{-2}$ (c), $50 \mathrm{MeV}{ }^{63} \mathrm{Cu}$ ions: 1.5 $\times 10^{13} \mathrm{~cm}^{-2}$ (d), $2.2 \times 10^{13} \mathrm{~cm}^{-2}$ (e), $235 \mathrm{MeV}{ }^{84} \mathrm{Kr}$ ions: $1.0 \times 10^{13}$ $\mathrm{cm}^{-2}(\mathrm{f})$.

side of the substrates was irradiated to keep the film on the opposite side as a virgin reference sample. For all irradiations, the mean projected range of the ions (see Table V) was higher than the film thicknesses. The major irradiation characteristics computed with the SRIM-96 code $^{14}$ are also displayed in Table V. It is seen that the mean electronic stopping powers $\left(S_{e}\right)$ are larger than the threshold for track formation $(4.5 \mathrm{MeV} / \mu \mathrm{m})$ in this low ion velocity range, ${ }^{3}$ and at least two orders of magnitude larger than the mean nuclear stopping powers $\left(S_{n}\right)$.

The $300 \mathrm{~K}{ }^{57} \mathrm{Fe}$ CEM spectra of the irradiated doped and undoped films were measured at the various fluences. Moreover, the x-ray absorption spectra at the iron $K$ edge of the same as-grown and irradiated undoped films were recorded at $300 \mathrm{~K}$ in the fluorescence mode between 7050 and $7200 \mathrm{eV}$ by $0.5 \mathrm{eV}$ steps, and between 7000 and $7700 \mathrm{eV}$ by $2 \mathrm{eV}$ steps. The latter experiments were performed at LUREDCI (Orsay, France) on the EXAFS-IV beamline with a channel-cut monochromator at an incidence angle around $20^{\circ}$. Prior to the measurements, an energy calibration was done with an iron metal sample at the iron $K$ edge $(7112 \mathrm{eV})$ in the transmission mode. Then the spectra of reference com-

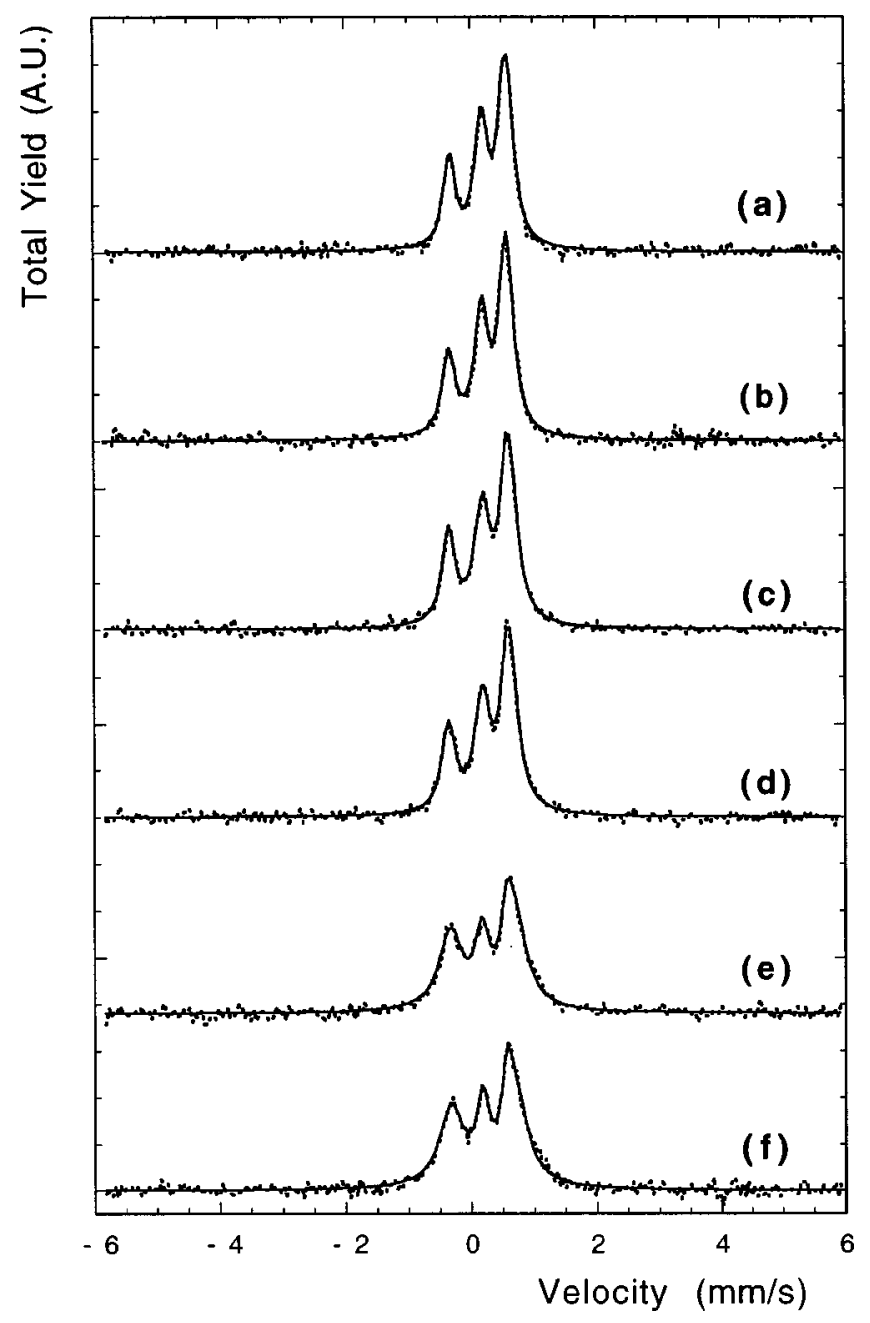

FIG. 2. $300 \mathrm{~K}$ conversion electron Mössbauer spectra of (111)-YIG:Ga thin epitaxial films: as-grown (a), irradiated with $50 \mathrm{MeV}^{32} \mathrm{~S}$ ions: $6 \times 10^{11}$ (b), $1 \times 10^{12}(\mathrm{c}), 3 \times 10^{12}(\mathrm{~d}), 7 \times 10^{12}(\mathrm{e}), 1 \times 10^{13} \mathrm{~cm}^{-2}(\mathrm{f})$.

pounds $\left(\alpha-\mathrm{Fe}_{2} \mathrm{O}_{3}\right.$ and $\mathrm{SrFeO}_{3-x}$ sinters $)$ were also recorded in the transmission mode as was done in the previous study ${ }^{5}$ in order to obtain the parameters (phase and amplitude) necessary for the standard x-ray absorption fine structure (XAFS) analysis.

\section{RESULTS}

\section{A. Mössbauer data}

The least-squares fit of the CEM spectra of the irradiated doped films (YIG:Ga and YIG:Sc) (Figs. 2-4) have been performed by using two quadrupolar doublets corresponding respectively to one octahedral and one tetrahedral $\mathrm{Fe}^{3+}$ site like the as-grown films as shown in Tables II-IV. An attempt was made to fit the spectra with three contributions corresponding to the octahedral, tetrahedral, and fivefold coordinated pyramidal iron sites like in a previous study. ${ }^{5}$ However, it did not improve significantly the reliability factor of the least-squares fits due to the large full width at half maximum $(\Gamma)$ of the lines of the pristine materials. In the case of the irradiated undoped YIG films, the CEM spectra 


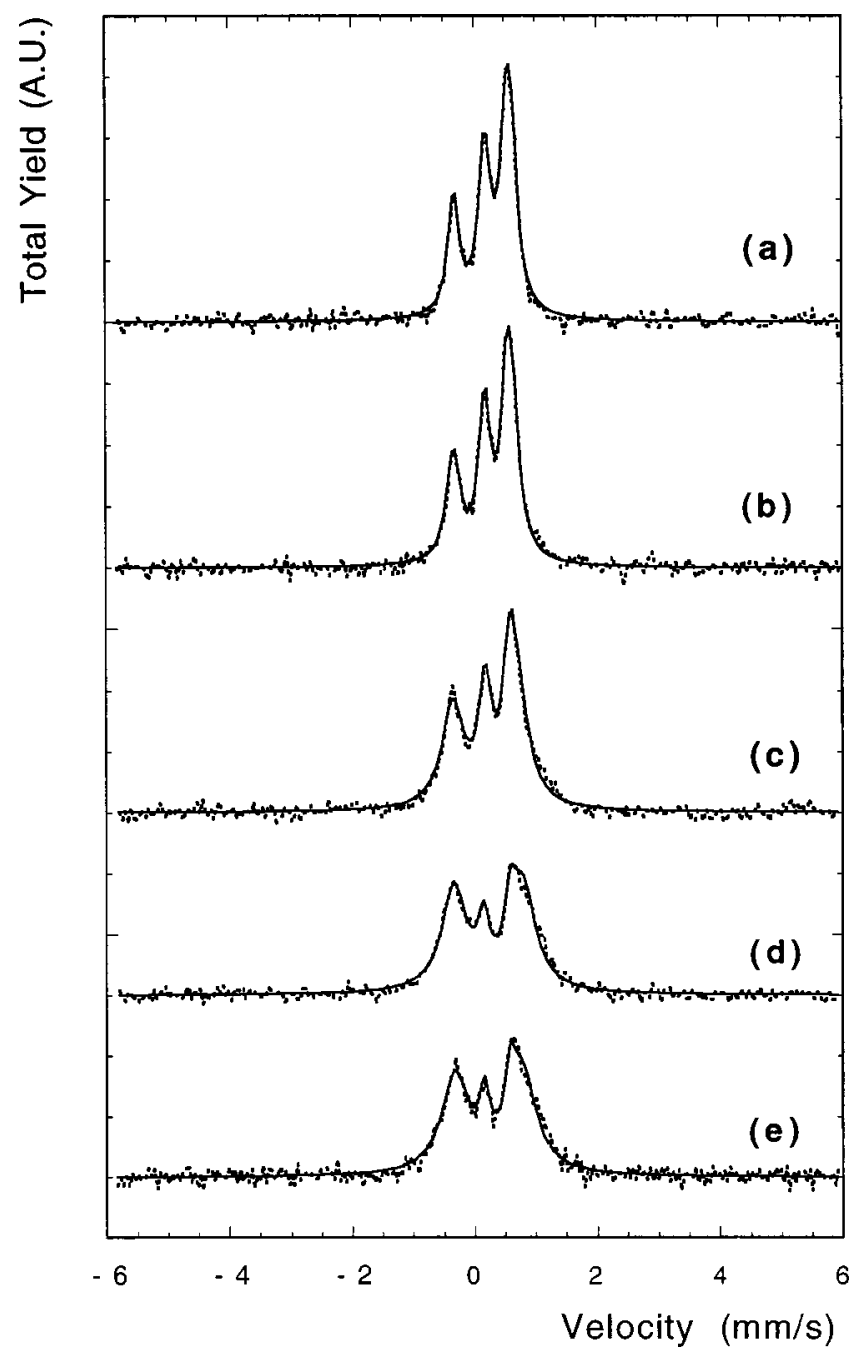

FIG. 3. $300 \mathrm{~K}$ conversion electron Mössbauer spectra of (111)-YIG:Ga thin epitaxial films: as-grown (a), irradiated with $50 \mathrm{MeV}^{63} \mathrm{Cu}$ ions: $2 \times 10^{11}$ (b), $3 \times 10^{11}(\mathrm{c}), 4 \times 10^{11}(\mathrm{~d}), 1 \times 10^{12} \mathrm{~cm}^{-2}(\mathrm{e})$.

(Fig. 1) exhibit only one symmetrical doublet which was least-squares fitted with only one quadrupolar doublet corresponding to one $\mathrm{Fe}^{3+}$ iron site (Table VI). Tables II-IV display the amorphous fractions $\left(f_{a}\right)$ deduced from a Poisson's law: $f_{a}=1-\exp (-A \phi t)$, where $A$ stands for the damage or amorphization cross-section given in Table $\mathrm{V}$, and $\phi t$ for the ion fluence. ${ }^{3}$ In case of undoped samples, HRTEM has

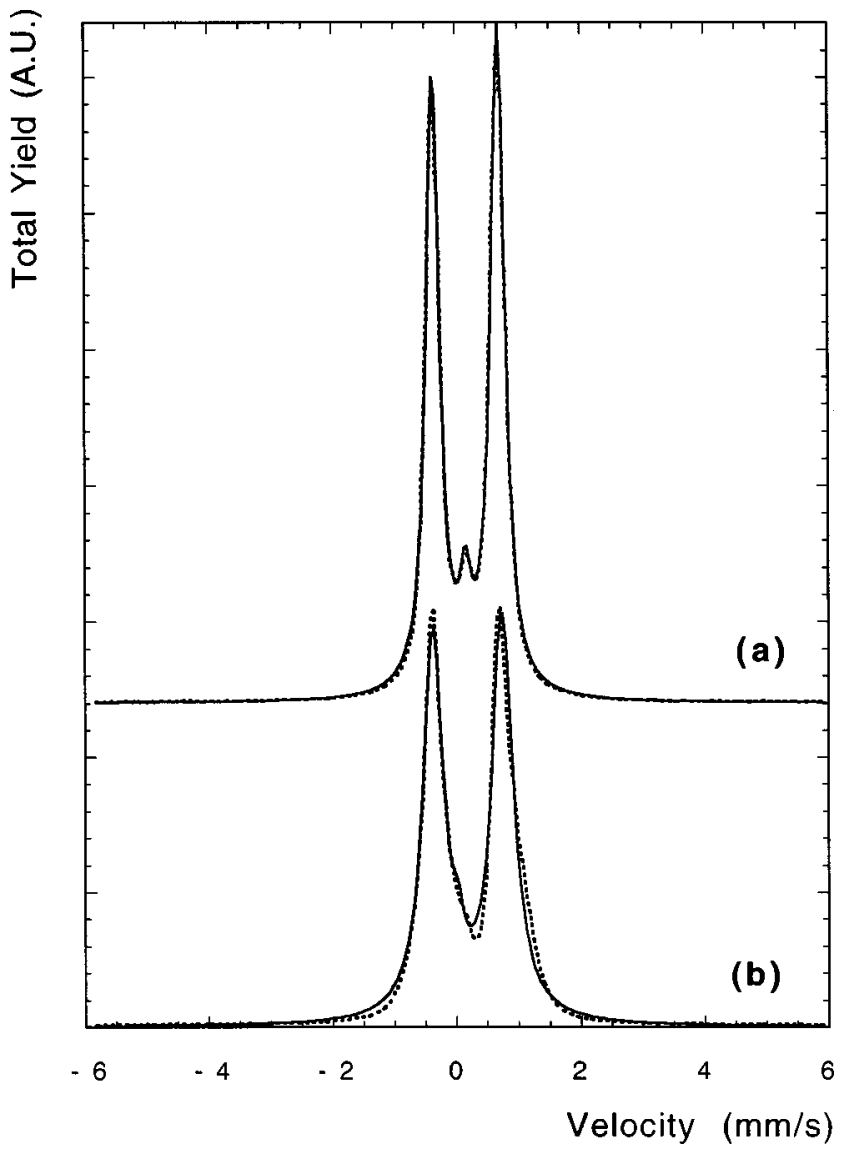

FIG. 4. $300 \mathrm{~K}$ conversion electron Mössbauer spectra of (111)-YIG:Sc thin epitaxial films: as-grown (a), irradiated with $50 \mathrm{MeV}{ }^{63} \mathrm{Cu}$ ions: $2 \times 10^{11} \mathrm{~cm}^{-2}(\mathrm{~b})$.

shown that the recrystallization process of the amorphous tracks is well under way after $50 \mathrm{MeV}^{32} \mathrm{~S}$ and $50 \mathrm{MeV}{ }^{63} \mathrm{Cu}$ ion irradiations at such high fluences (see Table VI) and that complete amorphization has occured instead with $235 \mathrm{MeV}$ ${ }^{84} \mathrm{Kr}$ ion irradiations at a fluence of $7 \times 10^{13} \mathrm{~cm}^{-2}$ without any recrystallization. ${ }^{6}$ High-resolution $\mathrm{x}$-ray diffraction data show that almost full amorphization of the YIG film $\left(f_{a}=99.5 \%\right)$ is obtained with the ${ }^{84} \mathrm{Kr}$ irradiations at $1 \times 10^{13} \mathrm{~cm}^{-2} \cdot{ }^{15}$ A similar recrystallization process was found to occur in films doped with calcium or silicon. ${ }^{9}$

The analysis of the Mössbauer spectra of YIG:Ga shows that in all cases the octahedral site fraction is apparently

TABLE II. Hyperfine parameters used for the least-squares fits of the $300 \mathrm{~K}{ }^{57} \mathrm{Fe} \mathrm{CEM}$ spectra of paramagnetic (111)-YIG:Ga epitaxial films irradiated with $50 \mathrm{MeV}{ }^{32} \mathrm{~S}$ ions at various fluences $(\phi t)$ (Fig. 2): amorphous fraction $\left(f_{a}\right)$, isomer shift (I.S.), quadrupolar splitting (Q.S.), full width at half maximum $(\Gamma)$, and fraction $(R)$ of the two sites. The standard deviation on the I.S. and Q.S. values is $0.01 \mathrm{~mm} / \mathrm{s}$.

\begin{tabular}{|c|c|c|c|c|c|c|c|c|c|}
\hline \multirow[b]{2}{*}{$\begin{array}{c}\phi t \\
{\left[\mathrm{~cm}^{-2}\right]}\end{array}$} & \multirow[b]{2}{*}{$\begin{array}{c}f_{a} \\
{[\%]}\end{array}$} & \multicolumn{4}{|c|}{ Octahedral site } & \multicolumn{4}{|c|}{ Tetrahedral site } \\
\hline & & $\begin{array}{c}\text { I.S. } \\
{[\mathrm{mm} / \mathrm{s}]}\end{array}$ & $\begin{array}{c}\text { Q.S. } \\
{[\mathrm{mm} / \mathrm{s}]}\end{array}$ & $\begin{array}{c}\Gamma \\
{[\mathrm{mm} / \mathrm{s}]}\end{array}$ & $\begin{array}{c}R \\
{[\%]}\end{array}$ & $\begin{array}{c}\text { I.S. } \\
{[\mathrm{mm} / \mathrm{s}]}\end{array}$ & $\begin{array}{c}\text { Q.S. } \\
{[\mathrm{mm} / \mathrm{s}]}\end{array}$ & $\begin{array}{c}\Gamma \\
{[\mathrm{mm} / \mathrm{s}]}\end{array}$ & $\begin{array}{c}R \\
{[\%]}\end{array}$ \\
\hline 0 & 0 & 0.51 & 0.43 & 0.24 & 61 & 0.21 & 0.84 & 0.22 & 39 \\
\hline $6 \times 10^{11}$ & 2 & 0.50 & 0.41 & 0.25 & 60 & 0.21 & 0.88 & 0.25 & 40 \\
\hline $1 \times 10^{12}$ & 3 & 0.52 & 0.46 & 0.29 & 59 & 0.21 & 0.90 & 0.24 & 41 \\
\hline $3 \times 10^{12}$ & 10 & 0.52 & 0.46 & 0.29 & 58 & 0.21 & 0.91 & 0.26 & 42 \\
\hline $7 \times 10^{12}$ & 22 & 0.48 & 0.40 & 0.24 & 32 & 0.30 & 1.04 & 0.24 & 68 \\
\hline $1 \times 10^{13}$ & 29 & 0.48 & 0.40 & 0.23 & 32 & 0.30 & 1.03 & 0.46 & 68 \\
\hline
\end{tabular}


TABLE III. Hyperfine parameters used for the least-squares fits of the $300 \mathrm{~K}{ }^{57} \mathrm{Fe}$ CEM spectra of paramagnetic (111)-YIG:Ga epitaxial films irradiated with $50 \mathrm{MeV}{ }^{63} \mathrm{Cu}$ ions at various fluences ( $\left.\phi t\right)$ (Fig. 3): amorphous fraction $\left(f_{a}\right)$, isomer shift (I.S.), quadrupolar splitting (Q.S.), full width at half maximum $(\Gamma)$, and fraction $(R)$ of the two sites. The standard deviation on the I.S. and Q.S. values is $0.01 \mathrm{~mm} / \mathrm{s}$.

\begin{tabular}{|c|c|c|c|c|c|c|c|c|c|}
\hline \multirow[b]{2}{*}{$\begin{array}{c}\phi t \\
{\left[\mathrm{~cm}^{-2}\right]}\end{array}$} & \multirow[b]{2}{*}{$\begin{array}{c}f_{a} \\
{[\%]}\end{array}$} & \multicolumn{4}{|c|}{ Octahedral site } & \multicolumn{4}{|c|}{ Tetrahedral site } \\
\hline & & $\begin{array}{c}\text { I.S. } \\
{[\mathrm{mm} / \mathrm{s}]}\end{array}$ & $\begin{array}{c}\text { Q.S. } \\
{[\mathrm{mm} / \mathrm{s}]}\end{array}$ & $\begin{array}{c}\Gamma \\
{[\mathrm{mm} / \mathrm{s}]}\end{array}$ & $\begin{array}{c}R \\
{[\%]}\end{array}$ & $\begin{array}{c}\text { I.S. } \\
{[\mathrm{mm} / \mathrm{s}]}\end{array}$ & $\begin{array}{c}\text { Q.S. } \\
{[\mathrm{mm} / \mathrm{s}]}\end{array}$ & $\begin{array}{c}\Gamma \\
{[\mathrm{mm} / \mathrm{s}]}\end{array}$ & $\begin{array}{c}R \\
{[\%]}\end{array}$ \\
\hline 0 & 0 & 0.51 & 0.43 & 0.24 & 61 & 0.21 & 0.84 & 0.22 & 39 \\
\hline $2 \times 10^{11}$ & 10 & 0.47 & 0.36 & 0.23 & 54 & 0.27 & 0.98 & 0.27 & 46 \\
\hline $3 \times 10^{11}$ & 15 & 0.49 & 0.40 & 0.25 & 38 & 0.29 & 1.06 & 0.43 & 62 \\
\hline $4 \times 10^{11}$ & 19 & 0.47 & 0.43 & 0.21 & 19 & 0.33 & 1.12 & 0.50 & 81 \\
\hline $1 \times 10^{12}$ & 41 & 0.48 & 0.42 & 0.20 & 18 & 0.33 & 1.10 & 0.54 & 82 \\
\hline
\end{tabular}

decreasing and the tetrahedral site fraction increasing when $\phi t$ increases (Fig. 5). The same behavior is found for YIG:Sc (Table IV). In the case of YIG:Ga, although the scaling of all the data with $f_{a}$ is not perfect (Fig. 6), a similar saturation of the site fractions occurs at $f_{a} \approx 20 \%$. Moreover, it is seen that the line of the tetrahedral iron sites broadens dramatically with increasing damage with a full width at half maximum $(\Gamma)$ reaching a value around twice as much as the pristine sample value, while that of the octahedral ones remains almost unaltered (Tables II-IV). Furthermore, the isomer shift (I.S.) and quadrupolar splitting (Q.S.) of the tetrahedral sites also increase significantly, while the I.S. of the octahedral ones decrease weakly versus $f_{a}$, with a saturation at $f_{a} \approx 20 \%$ for both iron sites (Fig. 7). However, no change of the iron oxidation state seems to occur. These observations are in agreement with the results of the previous study on undoped YIG which showed that the tetrahedral $\mathrm{Fe}^{3+}$ sites are preferentially damaged and new fivefold-coordinated (pyramidal) sites with I.S. $\approx 0.3 \mathrm{~mm} / \mathrm{s}$ at $300 \mathrm{~K}$ are formed in the fully amorphous phase ${ }^{5}$ obtained after irradiation with $3.5 \mathrm{GeV}^{132} \mathrm{Xe}$ ions at $5 \times 10^{12} \mathrm{~cm}^{-2}$. ${ }^{16}$ For the undoped YIG samples, the same quadrupolar doublet as in the $a-\mathrm{YIG}^{17}$ is found regardless of the ion and fluence: it seems then that there is no difference between the amorphous phase and the nanophase in this case (Fig. 1).

\section{B. X-ray absorption data}

The plot of the $\mathrm{x}$-ray fluorescence yield versus photon energy is displayed in Fig. 8 in the XANES range $(80 \mathrm{eV})$ near the iron $K$ edge for the as-grown and irradiated undoped YIG thin films. The X-ray absorption spectrum of $\alpha-\mathrm{Fe}_{2} \mathrm{O}_{3}$ is also plotted. Like in the previous study, ${ }^{5}$ a pre-edge peak is seen for all YIG samples, which is known to correspond to forbidden $(1 s \rightarrow 3 d)$ transitions that are very sensitive to the symmetry of the local order around iron. The peak increases when the number of noncentrosymmetrical sites including the tetrahedral sites increase. ${ }^{5}$ The magnification in Fig. 9 clearly shows that this pre-edge peak is quite strong in the virgin undoped YIG film with around $60 \%$ tetrahedral sites, and almost vanishes in $\alpha-\mathrm{Fe}_{2} \mathrm{O}_{3}$ with no tetrahedral sites at all and only slightly distorted octahedral ones. The irradiated samples (Table VI) spectra range in between those two: the peak height is smaller in the nanophase $\left({ }^{32} \mathrm{~S}\right.$ and ${ }^{63} \mathrm{Cu}$ irradiations) than in the amorphous phase $\left({ }^{84} \mathrm{Kr}\right.$ irradiation), in which it is smaller than in the as-grown single crystal, in agreement with the previous work. ${ }^{5}$ For the ${ }^{63} \mathrm{Cu}$ irradiation, the same peak height is found for the two fluences of 1.5 $\times 10^{13}$ (not shown) and $2.2 \times 10^{13} \mathrm{~cm}^{-2}$. This would mean that the fraction of tetrahedral sites decreases from the single crystal to the amorphous then to the nanocrystalline (nc) phase. However, no clear differences are seen in the XANES of all the irradiated samples (Fig. 8) which give overall similar features, like the CEM spectra. The EXAFS analysis was not feasible in the pristine films due to some Bragg diffraction lines of the single crystals at $20^{\circ}$ incidence angle. While the latter lines disappeared in the amorphized films, some were still present in the nanocrystallized ones, and prevented us from performing such an analysis.

\section{DISCUSSION}

\section{A. Local order and electronic structure}

It is known that the grain boundaries (GB) generally play a key role in the nanostructured materials: for a $10 \mathrm{~nm}$ grain size, the fraction of atoms in the GBs range between $15 \%$ for a GB thickness of $0.5 \mathrm{~nm}$, and $25 \%$ for a thickness

TABLE IV. Hyperfine parameters used for the least-squares fits of the $300 \mathrm{~K}{ }^{57} \mathrm{Fe}$ CEM spectra of paramagnetic (111)-YIG:Sc epitaxial films irradiated with $50 \mathrm{MeV}{ }^{63} \mathrm{Cu}$ ions at various fluences ( $\left.\phi t\right)$ (Fig. 4): amorphous fraction $\left(f_{a}\right)$, isomer shift (I.S.), quadrupolar splitting (Q.S.), full width at half maximum $(\Gamma)$, and fraction $(R)$ of the two sites. The standard deviation on the I.S. and Q.S. values is $0.01 \mathrm{~mm} / \mathrm{s}$.

\begin{tabular}{|c|c|c|c|c|c|c|c|c|c|}
\hline \multirow[b]{2}{*}{$\begin{array}{c}\phi t \\
{\left[\mathrm{~cm}^{-2}\right]}\end{array}$} & \multirow[b]{2}{*}{$\begin{array}{c}f_{a} \\
{[\%]}\end{array}$} & \multicolumn{4}{|c|}{ Octahedral site } & \multicolumn{4}{|c|}{ Tetrahedral site } \\
\hline & & $\begin{array}{c}\text { I.S. } \\
{[\mathrm{mm} / \mathrm{s}]}\end{array}$ & $\begin{array}{c}\text { Q.S. } \\
{[\mathrm{mm} / \mathrm{s}]}\end{array}$ & $\begin{array}{c}\Gamma \\
{[\mathrm{mm} / \mathrm{s}]}\end{array}$ & $\begin{array}{c}R \\
{[\%]}\end{array}$ & $\begin{array}{c}\text { I.S. } \\
{[\mathrm{mm} / \mathrm{s}]}\end{array}$ & $\begin{array}{c}\text { Q.S. } \\
{[\mathrm{mm} / \mathrm{s}]}\end{array}$ & $\begin{array}{c}\Gamma \\
{[\mathrm{mm} / \mathrm{s}]}\end{array}$ & $\begin{array}{c}R \\
{[\%]}\end{array}$ \\
\hline 0 & 0 & 0.51 & 0.62 & 0.22 & 11 & 0.26 & 1.04 & 0.26 & 89 \\
\hline $2 \times 10^{11}$ & 10 & 0.44 & 0.61 & 0.20 & 5 & 0.30 & 1.12 & 0.40 & 95 \\
\hline
\end{tabular}


TABLE V. Main characteristics of the room-temperature irradiations performed on the YIG epitaxial films: electronic stopping power $\left(S_{e}\right)$, nuclear stopping power $\left(S_{n}\right)$, mean projected range $\left(R_{p}\right)$, computed with the SRIM-96 code (Ref. 14) at the entrance ion energy $(E)$ and damage cross-section $(A)$ (Ref. 3).

\begin{tabular}{lccccc}
\hline \hline Ion & $\begin{array}{c}E \\
{[\mathrm{MeV}]}\end{array}$ & $\begin{array}{c}S_{e} \\
{[\mathrm{MeV} / \mu \mathrm{m}]}\end{array}$ & $\begin{array}{c}S_{n} \\
{[\mathrm{MeV} / \mu \mathrm{m}]}\end{array}$ & $\begin{array}{c}R_{p} \\
{[\mu \mathrm{m}]}\end{array}$ & $\begin{array}{c}A \\
{\left[\mathrm{~cm}^{2}\right]}\end{array}$ \\
\hline${ }^{32} \mathrm{~S}$ & 50 & 7 & $9.5 \times 10^{-3}$ & 8.4 & $3.5 \times 10^{-14}$ \\
${ }^{63} \mathrm{Cu}$ & 50 & 13 & $5.2 \times 10^{-2}$ & 6.3 & $5.3 \times 10^{-13}$ \\
${ }^{235} \mathrm{Kr}$ & 235 & 17 & $2.7 \times 10^{-2}$ & 17.5 & $5.3 \times 10^{-13}$ \\
\hline \hline
\end{tabular}

of $1.0 \mathrm{~nm} .{ }^{18}$ Since the GBs are also known to contain a large amount of defects in their cores, ${ }^{18,19}$ it is not so surprising that it would resemble the amorphous phase on a large length scale owing to the large GB concentration. However, on a smaller length scale, the two phases might differ in their local order which is seen in the fact that the atomic density is much lower in GB cores than in the bulk of glasses. ${ }^{19}$ However, in the case of irradiated undoped YIG, both the XANES and CEMS techniques do not see any difference between the amorphous and nc phases contrary to what was expected. HRTEM observations of the GB structure complemented with image simulations would certainly be of great help in this case. ${ }^{18}$ The only difference is observed in the analysis of the pre-edge peak showing that the tetrahedral iron sites are more damaged in the nc phase than in the amorphous phase. As said above, it was shown in the previous study that fivefold-coordinated sites are formed in $a$-YIG from the decrease of the pre-edge peak height. ${ }^{5}$ The present data would then hint to a further increase of the latter fivefold sites in the nc phase.

In the ion-irradiated YIG films, band tails are formed as a result of the loss of long-range order linked to the destruction of the tetrahedral sites which is reflected in the band gap shrinkage around $1 \mathrm{eV}$ seen in the optical absorption spectra. ${ }^{20}$ Moreover, the same behavior of the dc conductivity versus temperature varying according to an $\exp \left(-T_{0} / T\right)^{1 / 4}$ law was found with large $T_{0}$ values indicating a multiphonon polaron hopping conduction mechanism in the amorphous and nc phases. ${ }^{9,21}$ In order to account for the conductivity increase and magnetization decrease of ionimplanted or neutron bombarded YIG, it was postulated that a fraction of $\mathrm{Fe}^{3+}$ in the tetrahedral sites might be converted to $\mathrm{Fe}^{2+},{ }^{22}$ that would enhance polaron hopping between

TABLE VI. Hyperfine parameters used for the least-squares fits of the 300 $\mathrm{K}{ }^{57} \mathrm{Fe}$ CEM spectra of the undoped (111)-YIG epitaxial films irradiated with the different ions of energy $E$ at various fluences $(\phi t)$ (Fig. 1): isomer shift (I.S.), quadrupolar splitting (Q.S.), full width at half maximum ( $\Gamma)$. The standard deviation on the I.S. and Q.S. values is $0.01 \mathrm{~mm} / \mathrm{s}$.

\begin{tabular}{lccccc}
\hline \hline & $\begin{array}{c}E \\
\text { Ion }\end{array}$ & $\begin{array}{c}\phi t \\
{[\mathrm{MeV}]}\end{array}$ & $\begin{array}{c}\text { I.S. } \\
{[\mathrm{mm} / \mathrm{s}]}\end{array}$ & $\begin{array}{c}\text { Q.S. } \\
{[\mathrm{mm} / \mathrm{s}]}\end{array}$ & $\begin{array}{c}\Gamma \\
{[\mathrm{mm} / \mathrm{s}]}\end{array}$ \\
\hline${ }^{32} \mathrm{~S}$ & 50 & $3.7 \times 10^{14}$ & 0.40 & 1.15 & 0.54 \\
${ }^{32} \mathrm{~S}$ & 50 & $7.0 \times 10^{14}$ & 0.41 & 1.13 & 0.57 \\
${ }^{63} \mathrm{Cu}$ & 50 & $1.5 \times 10^{13}$ & 0.40 & 1.18 & 0.56 \\
${ }^{63} \mathrm{Cu}$ & 50 & $2.2 \times 10^{13}$ & 0.40 & 1.16 & 0.57 \\
${ }^{84} \mathrm{Kr}$ & 235 & $1.0 \times 10^{13}$ & 0.40 & 1.17 & 0.56 \\
\hline \hline
\end{tabular}

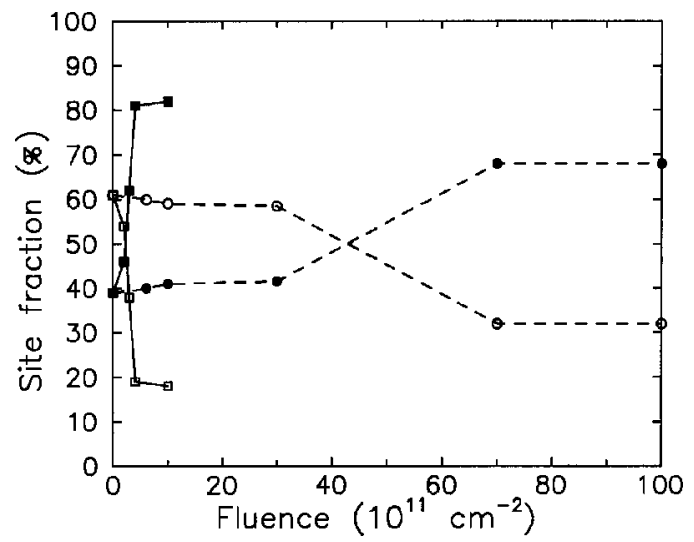

FIG. 5. Fractions $(R)$ of iron sites in (111)-YIG:Ga thin epitaxial films vs the ion fluence $(\phi t)$ after $50 \mathrm{MeV}{ }^{32} \mathrm{~S}$ ion irradiations (dashed lines): octahedral (open circles) tetrahedral (full circles), and $50 \mathrm{MeV}{ }^{63} \mathrm{Cu}$ ion irradiations (solid lines): octahedral (open squares) tetrahedral (full squares). The lines are guides to the eyes.

$\mathrm{Fe}^{3+}$ and $\mathrm{Fe}^{2+}$. The present results show that it is not the case, in agreement with previous studies. ${ }^{5,23}$ However, the decrease of the pre-edge peak height correlated with the increase of fivefold-coordinated defects in the amorphous and nc phases is consistent with the conductivity increase from the single crystal to the amorphous phase, ${ }^{24}$ then to the nc phase. $^{7}$

In a previous work, we also raised some doubts on the YIG phase stability, although the few discontinuous electron diffraction rings ascribed to the nc phase could be indexed in the cubic YIG crystal structure (space group: Ia3d) as (400), (420), (611), (631), and (732). ${ }^{6,7}$ Moreover, it is to be noted that the overall stoichiometry was not changed even at very high fluences $\left(7.5 \times 10^{13} \mathrm{~cm}^{-2}\right)$ with $50 \mathrm{MeV}{ }^{63} \mathrm{Cu}$ ion irradiation. ${ }^{7}$ Actually, it is known that $\mathrm{Y}_{3} \mathrm{Fe}_{5} \mathrm{O}_{12}$ starts to decompose under high pressure $(0.8 \mathrm{GPa})$ and high temperature $(630 \mathrm{~K})$ into $\mathrm{YFeO}_{3}$ (orthoferrite) and $\alpha$ - $\mathrm{Fe}_{2} \mathrm{O}_{3}$ (haematite) ${ }^{13}$ which both do not contain tetrahedral sites. It was found indeed that the (200), (122), (212), and (240) diffraction lines of $\mathrm{YFeO}_{3}$ with an orthorhombic crystal

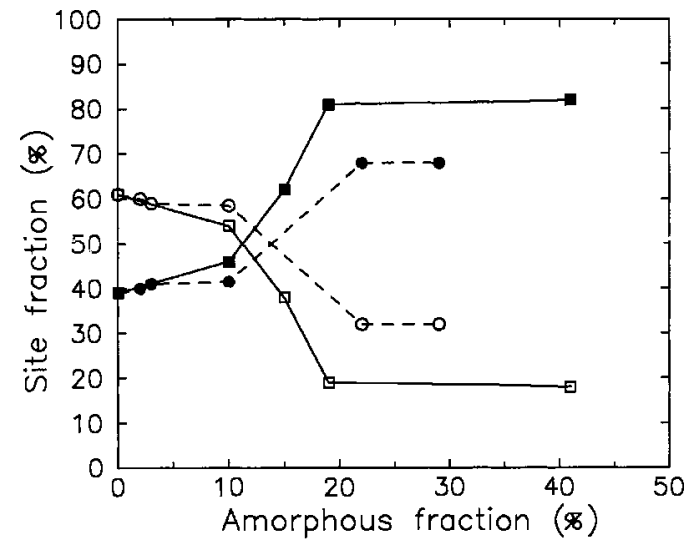

FIG. 6. Fractions $(R)$ of the iron sites in (111)-YIG:Ga thin epitaxial films vs the amorphous fraction $\left(f_{a}\right)$ after $50 \mathrm{MeV}^{32} \mathrm{~S}$ ion irradiations (dashed lines): octahedral (open circles) tetrahedral (full circles), and $50 \mathrm{MeV}{ }^{63} \mathrm{Cu}$ ion irradiations (solid lines): octahedral (open squares) tetrahedral (full squares). The lines are guides to the eyes. 


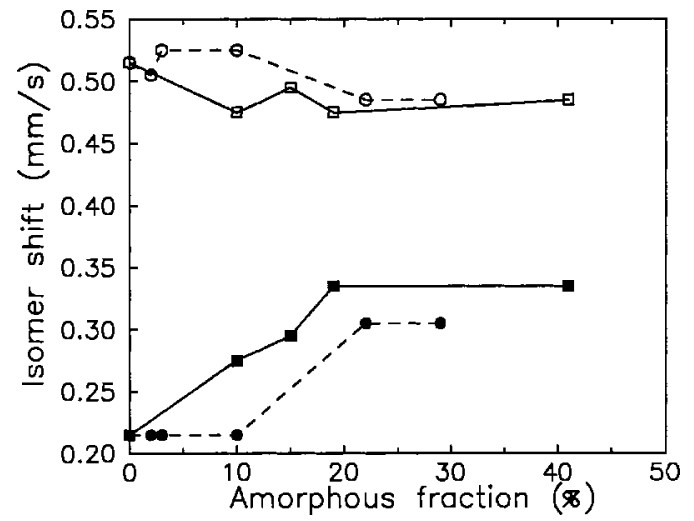

FIG. 7. Isomer shift (I.S.) of the iron sites in (111)-YIG:Ga thin epitaxial films vs the amorphous fraction $\left(f_{a}\right)$ after $50 \mathrm{MeV}{ }^{32} \mathrm{~S}$ ion irradiations (dashed lines): octahedral (open circles) tetrahedral (full circles), and 50 $\mathrm{MeV}{ }^{63} \mathrm{Cu}$ ion irradiations (solid lines): octahedral (open squares) tetrahedral (full squares). The lines are guides to the eyes.

structure (space group: Pnma) were close to that of $\mathrm{Y}_{3} \mathrm{Fe}_{5} \mathrm{O}_{12}$ mentioned above, and could be used for indexing the nc phase diffraction rings. Such a phase change could also explain the disappearance of the tetrahedral sites in the nanophase with respect to the amorphous phase, in the undoped as well as in the doped YIG films.

We have attempted to address this ion-beam induced recrystallization process in the frame of the thermal spike concept, previously used for modeling the amorphization pro-

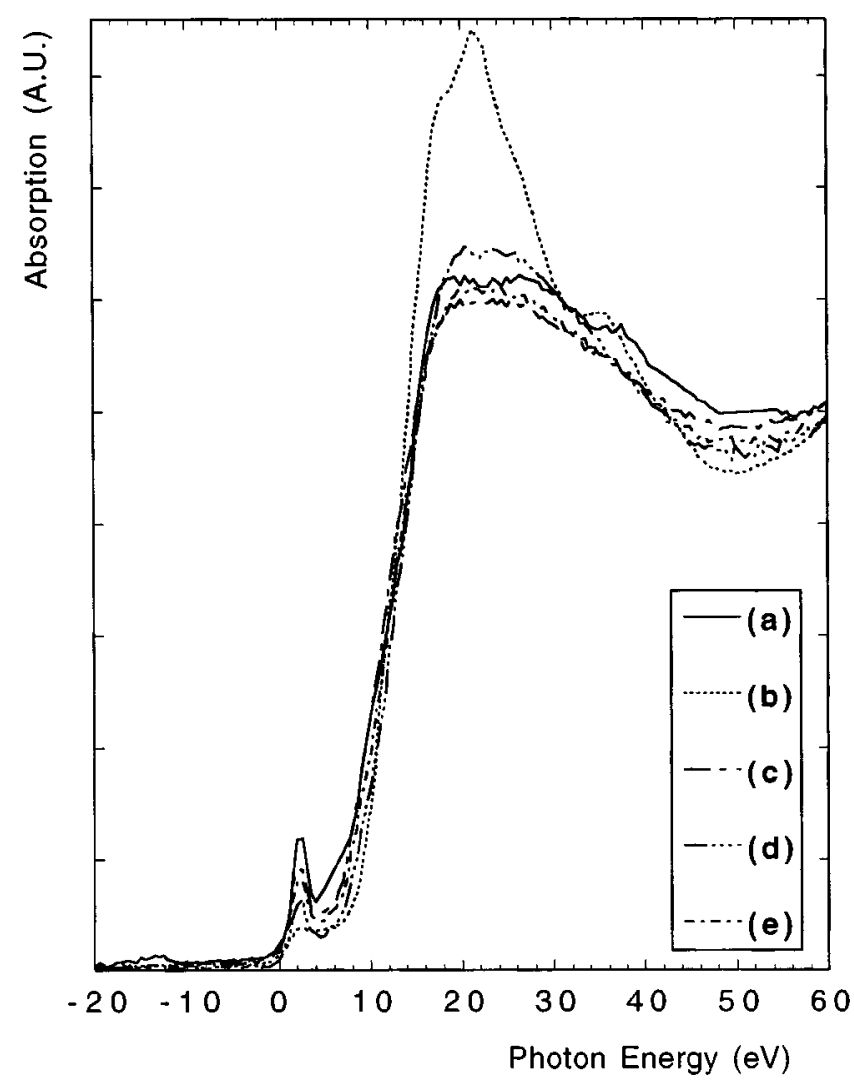

FIG. 8. X-ray fluorescence spectra of undoped (111)-YIG thin epitaxial films at the iron $K$ edge: as-grown (a), irradiated with $235 \mathrm{MeV}^{84} \mathrm{Kr}$ ions $\left(1.0 \times 10^{13} \mathrm{~cm}^{-2}\right)(\mathrm{c}), 50 \mathrm{MeV}^{32} \mathrm{~S}$ ions $\left(3.7 \times 10^{14} \mathrm{~cm}^{-2}\right)(\mathrm{d}), 50 \mathrm{MeV}{ }^{63} \mathrm{Cu}$ ions $\left(2.2 \times 10^{13} \mathrm{~cm}^{-2}\right)$ (e). X-ray absorption spectrum of $\alpha-\mathrm{Fe}_{2} \mathrm{O}_{3}$ (b).

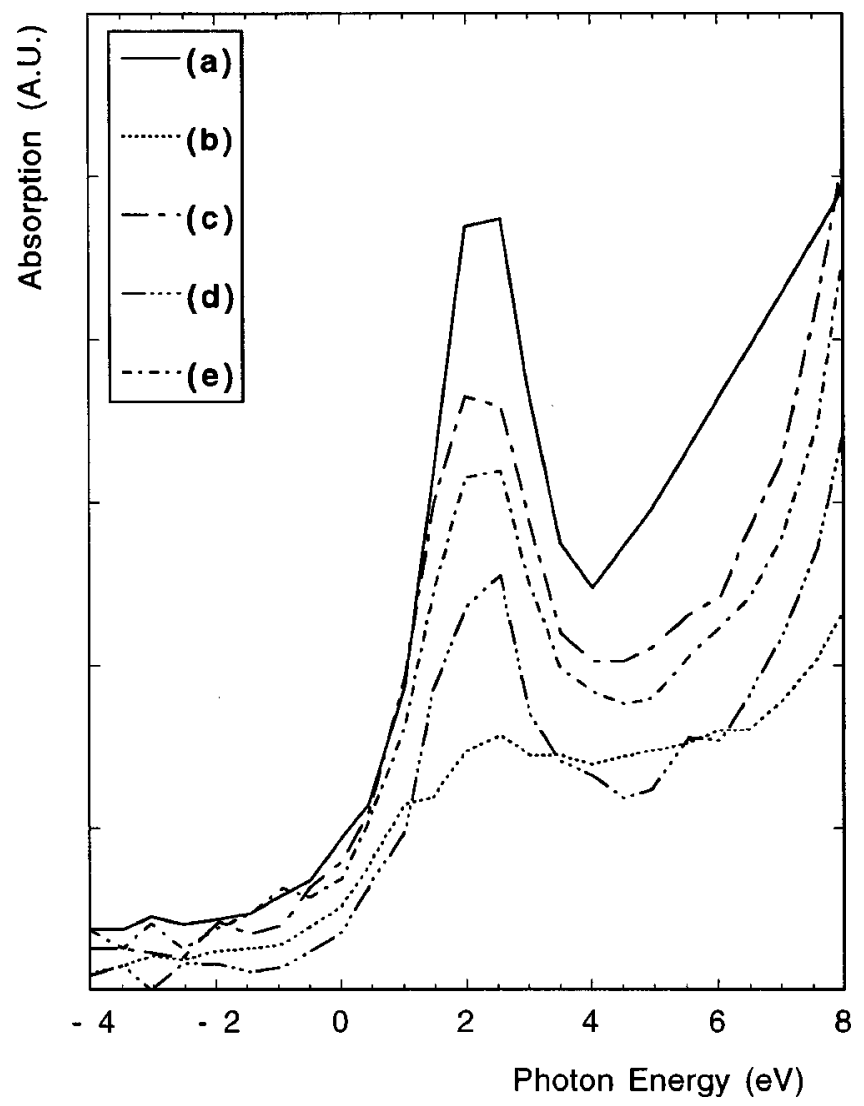

FIG. 9. Pre-edge peak of undoped (111)-YIG thin epitaxial films at the iron $K$ edge: as-grown (a), irradiated with $235 \mathrm{MeV}{ }^{84} \mathrm{Kr}$ ions $(1.0$ $\left.\times 10^{13} \mathrm{~cm}^{-2}\right)(\mathrm{c}), 50 \mathrm{MeV}^{32} \mathrm{~S}$ ions $\left(3.7 \times 10^{14} \mathrm{~cm}^{-2}\right)(\mathrm{d}), 50 \mathrm{MeV}^{63} \mathrm{Cu}$ ions $\left(2.2 \times 10^{13} \mathrm{~cm}^{-2}\right.$ ) (e); pre-edge peak of $\alpha-\mathrm{Fe}_{2} \mathrm{O}_{3}$ (b).

cess in the ion tracks. ${ }^{7}$ From our simulations, it was shown that the formation of a nanophase could occur due to ion impacts on the amorphous tracks due to a smaller quench rate of the melt and melting wave-front velocity in the case of amorphous YIG with respect to the pristine crystalline phase. However, in these simplified calculations, the occurrence of a decomposition of the melt superheated up to a maximum temperature larger in the amorphous phase than in the crystalline phase could not be taken into account. The possibility that such a phase change would have happened in the thermal spike is thus an open question. ${ }^{9}$ However, neither grain coarsening nor amorphization of the nc phase was seen even at very high fluences $\left(2 \times 10^{14} \mathrm{~cm}^{-2}\right.$ with $\left.50 \mathrm{MeV}{ }^{32} \mathrm{~S}\right) .{ }^{6}$ This is probably due to the stability and inherent resistance to grain growth of the nanostructures stemming from their narrow grain size distribution and low energy GB structures. ${ }^{18}$

\section{B. Magnetic behavior}

Another interesting issue concerns the magnetic properties of the nc phase. As seen by the CEMS data, the same paramagnetic behavior as in the $a$-YIG phase are found, in agreement with the saturation magnetization data. ${ }^{25}$ Around the same hyperfine parameters are obtained (Table VI) as in 
the $a$-YIG formed by $2.9 \mathrm{GeV}{ }^{84} \mathrm{Kr}$ irradiation of sintered YIG, for which I.S. $=0.424 \mathrm{~mm} / \mathrm{s}$, Q.S. $=1.09 \mathrm{~mm} / \mathrm{s}$, and $\Gamma$ $=0.69 \mathrm{~mm} / \mathrm{s}$ at $300 \mathrm{~K}^{17}$

It has been shown that the critical size below which single magnetic domain formation can occur in YIG is around $34 \mathrm{~nm} .{ }^{26}$ Since no magnetic hyperfine field splitting occurs in the nc phase at room temperature, this means that the nc phase is in the superparamagnetic state with a blocking temperature $\left(T_{B}\right)$ smaller than $300 \mathrm{~K} .{ }^{27}$ Above $T_{B}$ fast relaxation of the magnetization occurs due to the thermal fluctuations with a characteristic time constant $(\tau)$ depending of the domain size, whereas below $T_{B}$ the magnetic moments are frozen along an easy axis. ${ }^{27} T_{B}$ is the temperature at which $\tau=\tau_{m}$, the characteristic time of the measurement technique: for the ${ }^{57} \mathrm{Fe}$ Mössbauer spectroscopy, $\tau_{m}=2.5$ $\times 10^{-8} \mathrm{~s}^{26,27} T_{B}$ increases when $\tau_{m}$ decreases, or when the single domain size increases for a given $\tau_{m}$. So when $\tau$ $\gg \tau_{m}$ or $T<T_{B}$, the magnetic sextets of the bulk should appear again, while on the contrary for $\tau \ll \tau_{m}$ or $T>T_{B}$, only a quadrupolar doublet corresponding to the average of the grain magnetization over the space and time coordinates should be seen.

If there are no interactions between particles, in the dilute case, $\tau$ is given by the relationship $\tau=\tau_{0} \exp \left(K_{u} V / k T\right)$, where $K_{u}$ stands for the effective uniaxial anisotropy energy constant, $V$ the particle volume, $k$ the Boltzmann's constant, and $\tau_{0}$ a prefactor around $10^{-9} \mathrm{s.}^{27} \tau^{-1}$ is the probability of magnetization reversal that needs to overcome the energy barrier $E_{B}=K_{u} V$ corresponding to the maximum anisotropy energy. For example, in the case of magnetite $\left(\mathrm{Fe}_{3} \mathrm{O}_{4}\right.$ with $K_{1}=-1.1 \times 10^{5} \mathrm{erg} / \mathrm{cm}^{3}$ ) particles of around $6 \mathrm{~nm}$ diameter, $T_{B} \approx 180 \mathrm{~K}$, while for around $10 \mathrm{~nm}, T_{B}>350 \mathrm{~K}$, as seen by the Mössbauer spectroscopy, while in the case of pure iron $\left(K_{1}=4.1 \times 10^{5} \mathrm{erg} / \mathrm{cm}^{3}\right)$ particles of $10 \mathrm{~nm}$ diameter, a calculation gives $T_{B}$ around $100 \mathrm{~K} \cdot{ }^{27}$ However, practically speaking, there is often a distribution of relaxation times due to the size distribution which renders difficult the determination of $T_{B}$. Moreover, in case of dipolar particle interactions in dense systems, $\tau$ is decreased and the Arrhenius approximation does not hold, as was seen for $\gamma-\mathrm{Fe}_{2} \mathrm{O}_{3}$ nanoparticles dispersed in a solvent with a variable concentration. ${ }^{28}$

In the present case of YIG nanoparticles with a mean diameter of $10 \mathrm{~nm}$, assuming that the interactions between grains are negligible and taking the anisotropy constant along the $\langle 111\rangle$ easy axis $\left(K_{1}=-6.7 \times 10^{3} \mathrm{erg} / \mathrm{cm}^{3}\right)$ for $K_{u}$ yields a mean value of the relaxation time $\tau$ at $T=300 \mathrm{~K}$ close to $\tau_{0}$, i.e., clearly smaller than $\tau_{m}$. This corresponds to $T_{B} \ll 300 \mathrm{~K}$ : so it means that the nanophase should behave like a superparamagnet at room temperature.

A similar behavior occurs in the $a$-YIG phase where a magnetic sextet is seen below a freezing temperature $\left(T_{f}\right)$ around $70 \mathrm{~K}^{5,17}$ The magnetic susceptibility and the zerofield cooled (ZFC) and field-cooled (FC) magnetization measurements have shown that it corresponds to a speromagnetic ordering with an antiferromagnetic coupling. ${ }^{29}$ In such a case the spins are locked into random orientations below $T_{f}$ and the net magnetization is zero. ${ }^{30}$ However, a fraction smaller than $5 \%$ was found to be metamagnetic which is also antiferromagnetic at $5 \mathrm{~K}$. It becomes ferromagnetic under a weak applied magnetic field that decreases when temperature is lowered. ${ }^{29}$ It was concluded that this small metamagnetic fraction results from uncomplete track overlap even at high fluences due to the Poisson's law. The definitive proof of such a speromagnetic ordering in our case would need further in-field Mössbauer experiments at low temperature.

In the case of the nc phase examined here, it is difficult from the present results to sort out the contribution of the grain bulk supposedly superparamagnetic from the contribution of the disordered GB cores which could also lead to an amorphous-like behavior. Moreover, in case of a phase decomposition as mentioned above, the orthoferrite and haematite are both antiferromagnets at $300 \mathrm{~K}$ but could also lead to a paramagnetic Mössbauer spectrum below a small particle size: for example for $\alpha-\mathrm{Fe}_{2} \mathrm{O}_{3}$, a quadrupolar doublet is found below $10 \mathrm{~nm}^{27}$ Low-temperature CEM and ZFC and FC magnetic susceptibility measurements are necessary to clear up this point.

\section{CONCLUSIONS}

Thin epitaxial films of yttrium iron garnet $\left(\mathrm{Y}_{3} \mathrm{Fe}_{5} \mathrm{O}_{12}\right.$ or YIG) on nonmagnetic $\mathrm{Gd}_{3} \mathrm{Ga}_{5} \mathrm{O}_{12}$ substrates were irradiated with swift heavy ions $\left(50 \mathrm{MeV}{ }^{32} \mathrm{~S}, 50 \mathrm{MeV}{ }^{63} \mathrm{Cu}\right.$, and 235 $\mathrm{MeV}{ }^{84} \mathrm{Kr}$ ) in the electronic slowing down regime, above the amorphous track-formation threshold. The damage process leads either to an amorphous or a nanocrystalline (nc) state, depending on the irradiation conditions.

In the case of undoped (ferri)magnetic YIG thin films, no difference is found in the room-temperature CEMS data between the latter two phases which both have a paramagnetic behavior at room temperature. The amorphous phase is thought to be a speromagnet, whereas the nc phase appears to be a superparamagnet above the blocking temperature. The only difference is found in the x-ray absorption spectra at the iron $K$ edge showing that the local environment in the nc phase should be more centrosymmetrical than in the amorphous phase, which is already more centrosymmetrical than the pristine single crystal, due to the preferential destruction of the tetrahedral sites in the amorphization process, as found in the previous study on undoped (ferri)magnetic sintered YIG samples irradiated by $3.5 \mathrm{GeV}{ }^{132} \mathrm{Xe}$ ions. An explanation of this could be the formation of new sites, probably fivefold-coordinated ones, and/or a phase transformation occuring in the recrystallization process from the superheated melt by decomposing the garnet $\mathrm{Y}_{3} \mathrm{Fe}_{5} \mathrm{O}_{12}$ at high temperature and high pressure into the orthoferrite $\left(\mathrm{YFeO}_{3}\right)$ and haematite $\left(\alpha-\mathrm{Fe}_{2} \mathrm{O}_{3}\right)$ which both do not contain tetrahedral sites. In the case of paramagnetic gallium-(or scandium-) substituted films, the room-temperature ${ }^{57} \mathrm{Fe}$ conversion electron Mössbauer spectra (CEMS) also show that no change of the iron oxidation state occurs and that the tetrahedral $\mathrm{Fe}^{3+}$ sites are preferentially destroyed in the damage process corresponding to the formation of the fivefoldcoordinated ones, and/or phase decomposition.

\section{ACKNOWLEDGMENT}

The authors are indebted to Professor P. Paroli (Università di Roma, Italy) for providing the YIG:Sc samples. 
${ }^{1}$ M. Toulemonde, S. Bouffard, and F. Studer, Nucl. Instrum. Methods Phys. Res. B 91, 168 (1994).

${ }^{2}$ P. Hansen, H. Heitmann, and P. H. Smit, Phys. Rev. B 26, 3539 (1982).

${ }^{3}$ A. Meftah, F. Brisard, J. M. Costantini, M. Hage-Ali, J. P. Stoquert, F. Studer, and M. Toulemonde, Phys. Rev. B 48, 920 (1993).

${ }^{4}$ A. Meftah, J. M. Costantini, M. Djebara, N. Khalfaoui, J. P. Stoquert, F. Studer, and M. Toulemonde, Nucl. Instrum. Methods Phys. Res. B 122, 470 (1997)

${ }^{5}$ F. Studer, Ch. Houpert, M. Toulemonde, and E. Dartyge, J. Solid State Chem. 91, 238 (1991).

${ }^{6}$ J. M. Costantini, F. Ravel, F. Brisard, M. Caput, and C. Cluzeau, Nucl. Instrum. Methods Phys. Res. B 80/81, 1249 (1993).

${ }^{7}$ J. M. Costantini, F. Brisard, M. Toulemonde, and F. Studer, Nucl. Instrum. Methods Phys. Res. B 122, 514 (1997).

${ }^{8}$ J. M. Costantini, F. Brisard, A. Meftah, M. Toulemonde, and F. Studer, Radiat. Eff. Defects Solids 126, 233 (1993).

${ }^{9}$ J. M. Costantini, J. M. Desvignes, and M. Toulemonde, J. Appl. Phys. (accepted).

${ }^{10}$ J. M. Desvignes, J. M. Cerceau, V. B. Kratchenko, and H. Le Gall, J. Cryst. Growth 56, 132 (1982).

${ }^{11}$ G. Balestrino, P. Paroli, B. Antonini, G. Luce, and B. Maturi, J. Cryst. Growth 85, 270 (1987).

${ }^{12}$ G. Marest, A. Pérez, P. Gerard, and J. M. Mackowski, Phys. Rev. B 34, 4831 (1986).

${ }^{13}$ G. Winkler, Magnetic Garnets, Vieweg Tracts in Pure and Applied Physics (Vieweg, Braunschweig, 1980), Vol. 5.
${ }^{14}$ J. P. Biersack and L. G. Haggmark, Nucl. Instrum. Methods 174, 257 (1980).

${ }^{15}$ J. M. Costantini, F. Brisard, L. Autissier, M. Caput, and F. Ravel, J. Phys. D: Appl. Phys. 26, A57 (1993).

${ }^{16}$ F. Studer, Ch. Houpert, H. Pascard, R. Spohr, J. Vetter, J. Yun Fan, and M. Toulemonde, Radiat. Eff. Defects Solids 116, 59 (1991).

${ }^{17}$ F. Studer, N. Nguyen, G. Fuchs, and M. Toulemonde, Hyperfine Interact. 29, 1287 (1986)

${ }^{18}$ R. W. Siegel, J. Phys. Chem. Solids 55, 1097 (1994).

${ }^{19}$ H. Gleiter, Prog. Mater. Sci. 33, 223 (1989); Adv. Mater. 4, 474 (1992).

${ }^{20}$ J. M. Costantini, F. Brisard, and A. Pérez, Philos. Mag. 71, 41 (1995).

${ }^{21}$ J. M. Costantini, F. Brisard, J. L. Flament, Philos. Mag. B 65, 873 (1992).

${ }^{22}$ H. Pascard, Phys. Rev. B 33, 7252 (1986).

${ }^{23}$ J. M. Grenèche, H. Pascard, and J. R. Regnard, Solid State Commun. 65, 713 (1988).

${ }^{24}$ J. M. Costantini, F. Brisard, J. L. Flament, D. Bourgault, L. Sinopoli, and J. L. Uzureau, Nucl. Instrum. Methods Phys. Res. B 59/60, 600 (1991).

${ }^{25}$ J. M. Costantini, F. Brisard, J. L. Flament, A. Meftah, M. Toulemonde, and M. Hage-Ali, Nucl. Instrum. Methods Phys. Res. B 65, 568 (1992).

${ }^{26}$ T. V. Dimitrieva, I. S. Zhebulev, I. S. Lyubutin, O. L. Polushchenko, V. G. Tersuev, and R. I. Chalabov, Phys. Chem. Mech. Surf. 5, 1589 (1990).

${ }^{27}$ J. L. Dormann, Rev. Phys. Appl. 16, 275 (1981).

${ }^{28}$ P. Prené, E. Tronc, J. P. Jolivet, J. Livage, R. Cherkaoui, M. Noguès, and J. L. Dormann, Hyperfine Interact. 93, 1409 (1994).

${ }^{29}$ Ch. Houpert, Ph.D. thesis, Université de Caen (1989).

${ }^{30}$ C. M. Hurd, Contemp. Phys. 23, 469 (1982). 